\title{
Propagation challenges in 5G millimeter wave implementation
}

\author{
Siti Fatimah Nordin', Zuhanis Mansor², Aizat Faiz Ramli ${ }^{3}$, Hafiz Basarudin ${ }^{4}$ \\ ${ }^{1,2,3}$ Research and Innovation Department, Universiti Kuala Lumpur British Malaysian Institute, Malaysia \\ ${ }^{4}$ Communication Technology Department, Universiti Kuala Lumpur British Malaysian Institute, Malaysia
}

\begin{tabular}{|c|c|}
\hline Article Info & ABSTRACT \\
\hline Article history: & \multirow{11}{*}{$\begin{array}{l}\text { With current technology advances, implementing millimeter wave in real life } \\
\text { had became more promising and demanding. However, before millimeter } \\
\text { wave can be deployed, there were several challenges in terms of technical, } \\
\text { path loss and shadowing. This paper provides review on the challenges that } \\
\text { might occurs when implementing } 5 \mathrm{G} \text { millimeter wave. An overview of LTE- } \\
\text { Advanced and millimeter wave is made to provide further understanding. A } \\
\text { critical analysis was also made to identify the problem especially in rain and } \\
\text { haze attenuation, if addressed, will help mobile service provider to overcome } \\
\text { the problem. }\end{array}$} \\
\hline Received Dec 25, 2018 & \\
\hline Revised Feb 16, 2019 & \\
\hline Accepted Feb 28, 2019 & \\
\hline Keywords: & \\
\hline $5 \mathrm{G}$ & \\
\hline Channel modelling & \\
\hline Haze attenuation & \\
\hline LTE-Advanced & \\
\hline Millimeter wave & \\
\hline Rain attenuation & \\
\hline \multicolumn{2}{|l|}{ Corresponding Author: } \\
\hline \multicolumn{2}{|c|}{$\begin{array}{l}\text { Siti Fatimah Nordin, } \\
\text { Department of Research and Innovation, } \\
\text { Universiti Kuala Lumpur British Malaysian Institute, } \\
\text { Batu 8, Jalan Sungai Pusu, 53100, Gombak, Selangor Darul Ehsan, Malaysia. } \\
\text { Email: sfatimah.nordin@ @.unikl.edu.my }\end{array}$} \\
\hline
\end{tabular}

\section{INTRODUCTION}

Nowadays, it is quite challenging for mobile service provider in order to meet the expectation for faster wireless data services. Modern wireless network such as Long Term Evolution (LTE) was introduced to the public to meet customers need on wireless network. As stated by 3rd Generation Partnership Project (3GPP), the Universal Mobile Telecommunications System (UMTS) Long Term Evolution (LTE) Release 8 can provide data rates up to $300 \mathrm{Mbps}$ on downlinks and $75 \mathrm{Mbps}$ on uplinks. Based on the requirement from International Mobile Telecommunications-Advanced (IMT-A), few improvements have been studied to provide improvements to current LTE Release 8. These improvements are considered as part of LTEAdvanced [1-2].

Due to technology advances, the usage of mobile data growth have rapidly increase at over $50 \%$ and is expected to expand even more for the next coming decade [3-5]. However, the growth of mobile traffic have been challenging to the wireless service provider in order to overcome a global bandwidth shortage [6-8]. Thus, the LTE-Advanced is actively researching fifth generation (5G) mobile communication system to cope with current demand. Figure 1 illustrates the evolution of mobile communication system towards $5 \mathrm{G}$.

The fifth generation or $5 \mathrm{G}$ has been highlighted to be the next era for mobile communication system. Although many technological advances has been implemented in fourth generation (4G) system such as orthogonal frequency-division multiplexing (OFDM), multiple-input multiple-output (MIMO) and etc. It is expected that the surging demand mobile data in the next decade can no longer accommodate the user data usage and latency requirement [8-9]. Thus, the development 5G network is introduces a promising frequency spectrum around 3-300 GHz better known as millimeter wave bands with wavelength range between 1 to $100 \mathrm{~mm}$. This spectrum is currently underutilized by mobile service provider. Figure 2 shows the frequency spectrum for both super high frequency (SHF) with a range of 3-30 GHz and 30-300 GHz spectrum for extremely high frequency (EHF). 


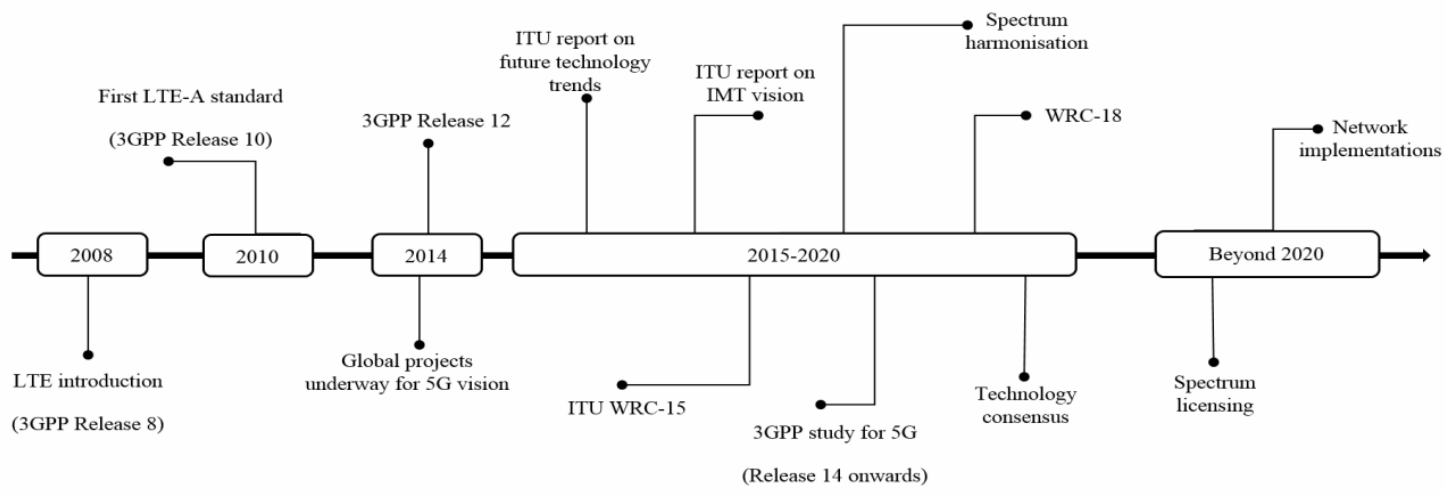

Figure 1. Timeline and the development towards 5G [10]

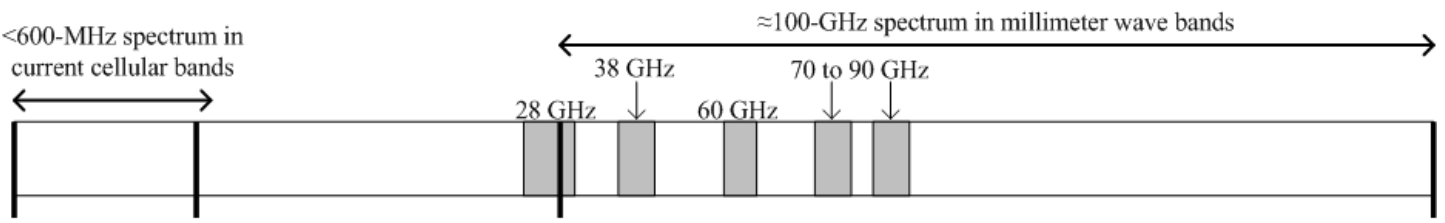

Figure 2. Frequency spectrum from $300 \mathrm{MHz}-300 \mathrm{GHz}$

Millimeter wave historically has been considered expensive to be utilized thus only selected authorities such as governmental bodies to broadcast in this spectrum. Nowadays with current semiconductor technology advances, the cost has been greatly reduced which gives an opportunity for this spectrum to be broadly used commercially.

However, the usage of millimeter wave have experience some challenges to be broadcast by mobile network operators. Millimeter wave path loss and shadowing are greatly impeded due to the reflection in building as well as absorption and scattering made by rain, haze and fog compared to the standard 4G spectrum bands $(2-8 \mathrm{GHz})$. Besides that, researchers also found few technical difficulties in order to implement millimeter wave. Although, many researchers have made breakthroughs to ensure the functionalities of the $5 \mathrm{G}$ millimeter wave communication system but none of them were actually been deployed to be used commercially. Most of the equipment was used for research purpose only. This paper will review the following key contributions in terms of channel propagation, antenna technology and also path loss and shadowing in urban and suburban area.

The rest of the paper is organized as follow. Section 2 will explained the technical challenges in order to implement $5 \mathrm{G}$ millimeter wave. Section 3 consist of challenges in terms of path loss and shadowing in $5 \mathrm{G}$ millimeter wave. Section 4 discussed on the rain and haze attenuation by comparing previous works. And finally Section 5 concluded this paper and suggested future work.

\section{TECHNICAL CHALLENGES IN IMPLEMENTING 5G MILLIMETER WAVE}

Implementing millimeter wave is always considered challenging by researchers. Until these days, millimeter wave have been primarily been used by military. To overcome the expected limitation of $4 \mathrm{G}$ networks, researchers have proposed the broadcast in millimeter wave spectrum. As aforementioned, implementation of millimeter wave in $5 \mathrm{G}$ are met with various challenges, this section provide a brief review on the technical challenges.

\subsection{Channel Propagation}

Currently, there are lots of effort in researching the channel measurement and modelling for $5 \mathrm{GHz}$ Wireless Local Area Network (WLAN) band [11-13] and 3-10GHz Ultra-wideband (UWB) band [14-17]. However research on the channel modulation of frequency above $60 \mathrm{GHz}$ is still limited. The authors in [18] stated that frequency above $60 \mathrm{GHz}$ have severe path loss that can limit the functionality of the system. This findings were echoed by researchers in [19-21]. Even though, there are solutions to this problem by the use of relays or regenerative repeaters. However, currently there is no specific channel that 
can address the $60 \mathrm{GHz}$ which required spatial properties and can detected the effect of human movement. Current technology approaches only measured the angle of arrival of the received signal in corridor and desktop environment by using antenna array [22] and rotational directive antenna [23]. But the result may varies thus it required in-depth research on characterize and validation of these results.

Paper [18] also stated that all the channel models currently available are only for radio channel which making it hard due to it dependency on the antenna which only can be used for particular setup of an antenna. This paper suggested a research on propagation channel which excluded the effect of antenna [24] and explore the effect of a different type of antenna setups with different gain/bandwidth especially frequency at $60 \mathrm{GHz}$ and above. Referring to [25], it said that high gain antenna can greatly reduce the delay spread of the radio channel when both transmitter $(\mathrm{Tx})$ and receiver $(\mathrm{Rx})$ antennas are aligned. But, any minor error on the main lobe of the antenna may affect the direction of arrival of the signal [26-27]. Moreover, [18] also mention the effects of multipath suppression using circular polarization over linear polarization demonstrated on [28], needed more accurate measurement to produce a promising result for $60 \mathrm{GHz}$ frequency and above.

Referring to [29], it is mentioned that current research need to be more efficient and produce realistic measurement data because it was needed in the future for modification or extensions for available channel propagations. It also stated that the measurement approach should base on various frequency, spatial consistency, 3D, spherical waves, small cell communications and also new communication paradigms (e.g. Device-to-Device (D2D) or Machine-to-Machine (M2M)). The data need to be tested in millimeter wave especially frequency above $60 \mathrm{GHz}$. The data measurement should considered real life events such as vehicle-to-vehicle and crowded areas. It also emphasized that the data should be carried out for both indoor and outdoor situations.

Another notable mentions from [30] is the usage of large-scale antenna for directive communication and millimeter wave communication to be implemented on the 5G systems. Current channel models essentially need few improvement primarily in angular resolution and sub-path amplitude distribution. [30] proclaimed that large-scale antenna should use spherical wave instead of plane wave approximation. Therefore, millimeter wave especially at $60 \mathrm{GHz}$ is proposed to attain spectrum and spatial multiplexing gain but some the features like highly resolved angular properties and non-line-of-sight (NLOS) path loss require deeper understanding.

\subsection{Antenna Technology}

One of the main components that need to be analyzed in developing millimeter wave system is the antenna. Although, there are many type of antennas that had been developed and used, however, none of them are designed specifically for millimeter wave due to the requirements to be low cost, small in size, light weight and high gain. As stated by [18], $60 \mathrm{GHz}$ antennas were required to be operated with constant gain and high efficiency for wider frequency range which are 55-67 GHz. It also discussed on the beamforming of $60 \mathrm{GHz}$ can be accomplish using switched beam array or phase array. Both researchers of [31-32] proved that beam steering antenna can produced result around $14 \mathrm{dBi}$ with $20^{\circ}$ half power beam width (HPBW) meanwhile 4-element planar array have an average conversion loss less than $10.6 \mathrm{~dB}$ for all four channels. However, current antenna that had been developed are using larger phase array that can dispute other technical challenges meanwhile initial proposed requirement are small size, low cost, light weight and high gain which can only be achieve by thorough research.

\section{PATH LOSS AND SHADOWING IN 5G MILLIMETER WAV}

Path loss and shadowing are example of major challenges in implementing millimeter wave as stated by [33]. The free space path loss is highly dependence on the carrier frequencies, $f_{c}$. As the carrier frequencies increase, the free space path loss will also increase [33-34]. Shadowing can degrade the millimeter wave for example brick and human body can attenuate the signals around 40-80 dB and 20-35 dB r4espectively [8], [19], [35-38]. Besides that, according to [76], millimeter wave can severely attenuated can also be caused by rain, haze and fog through absorption and scattering.

\subsection{Urban and Suburban}

For the past few years, many researches had been conducted for various measurement of mm bands [3], [39-44] in order to evaluate path loss through different materials and buildings. The research made on [35] had experimented the reflection and path loss around building in urban area in New York City using 28 GHz. The authors used frequency at $28 \mathrm{GHz}$ due to it was underutilized [45] and have low atmospheric absorption and similar free space path loss with $1-2 \mathrm{GHz}$ cellular bands compare to 60GHz [7]. This paper also mentions that the research was made for both indoor and outdoor to investigate the value of reflections 
coefficients on several type of materials. The experiments used directional antenna whereas the distance between Tx and Rx was $5 \mathrm{~m}$ and also used broadband sliding correlator channel sounder that also been done in [45-48]. The authors stated that the path loss at outside environment shows higher path loss than indoor making it harder to utilized $28 \mathrm{GHz}$ spectrum for indoor-to-outdoor penetration.

Next, the authors in [49] had conducted an experiments to measure the line-of-sight (LOS) and nonline-of-sight (NLOS) scenarios in urban microcellular area at New York City and Austin, Texas. This paper majorly focusing on finding new suitable path loss model by referring the previous path loss model for frequencies spectrum at $28 \mathrm{GHz}$ and $38 \mathrm{GHz}$ This research used steerable antennas for Tx and Rx with different heights and gains for both frequencies. Besides that, the authors also used sliding correlator channel sounder in order to present conceive measurement results. It also mentions that the new path loss was distance dependence and it had been created by referring to the linear regression fits. The authors suggested to use higher gain antennas to compensate the additional path loss.

In [50], the authors focused on comparing the previous rural microcell (RMa) propagation models and current RMa path loss models which was introduced by the 3GPP for frequencies around 0.5 until 30 GHz. Thus, by comparing both of the results, the authors had developed new RMa path loss model which was more accurate and easier to be applied for different height of the transmitter antenna. The research also stated that it can be used for frequency from 0.5 until $100 \mathrm{GHz}$. RMa path loss model can only be used for transmitter above 35 meters as stated in [51-52] but for $73 \mathrm{GHz}$ RMa was designed to overcome the limitation for the previous RMa. Based on the research made in [50], it designed CIH path loss model by referring the previous CI path loss model considering the model was designed for several conditions. This paper concluded that the RMa that had been introduce by the 3GPP does not have any existing evidence. Below shows the mathematical form for $\mathrm{CIH}$ model which is same with the CIF model [53] and given here for $d_{0}=1 \mathrm{~m}$ :

$$
\begin{aligned}
& \operatorname{PL}^{\mathrm{CIH}}\left(f_{c}, d, h_{B S}\right)[\mathrm{dB}]=\operatorname{FSPL}\left(f_{c}, 1 m\right)[\mathrm{dB}] \\
& +10 n\left(1+b_{t x}\left(\frac{h_{B S}-h_{B 0}}{h_{B 0}}\right)\right) \log _{10}(d)+\chi_{\sigma} ; \\
& \text { where } d \geq 1 \mathrm{~m}
\end{aligned}
$$

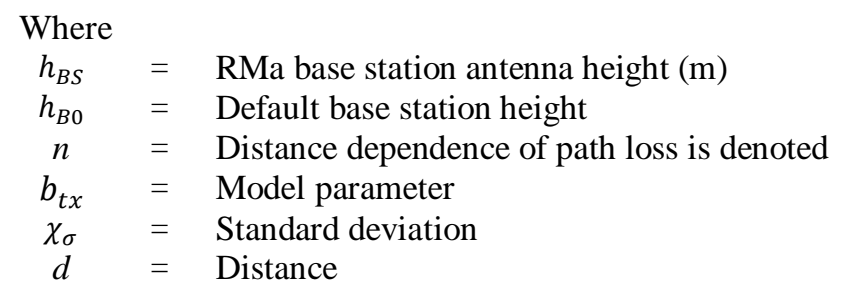

\subsection{Rain}

An attenuation caused by rain had become dominant fade mechanism on fixed links that operate above $10 \mathrm{GHz}$. In this paper [54], new joint rain fade simulation tool; GINSIM, was developed to compare the simulation results with ITU-R model and real radio links which covered United Kingdom and European area. This simulation tool was developed to replace the previous Hull Rain Fade Network Simulator (HRFNS) which include several upgrade in fade mechanism and etc. hydrometeors (raindrops, ice pellets, hail and complex mixed phase particles) can caused scattering and absorption at the radio links especially above $10 \mathrm{GHz}$ due to the size of the raindrop was the same with EHF band. Scattering can be divided into two which were Rayleigh scattering and Mie scattering. Rayleigh scattering can only be used when the particles is smaller than wavelength meanwhile Mie scattering is used when particles size were similar with the wavelength. However, this paper suggested to use Rayleigh scattering model which suitable for detecting rain scattering on microwave links. The author stated that specific attenuation using the power law Recommendation ITU-R P. 838-3 [55] will increase as the frequency and rain rate increase. Therefore, Nimrod data had been introduced with finer-scale spatial variation using multiscaling exponents

The rain rate is one of the main factor in determine the rain attenuation in microwave link. [76] agreed that rain can affect losses in transmission line for frequency above $10 \mathrm{GHz}$ due to scattering and absorption. In [56], the paper focused in analyzing rain attenuation and rain data for three years (2013-2015) in South Korea. The authors tested the experiments using six channel models which were ITU-R P. 530-16 [57], Da Silva Mello model [58], Moupfouma's model [59], Abdulrahman et. al [60], Lin model [61] and differential equation approach [62] by referring to the local environment and comparing all of the results. Usually, ITU-R P.530-16 was the most focuses models in many previous researches for example in [63-67]. Among all of six models ITU-R P. 530-16 showed a promising results because it had the closer estimation on 
rain attenuation on rain for both $38 \mathrm{GHz}$ and $75 \mathrm{GHz}$ frequencies. However, De Silva Mello and Abdulrahman et. al models also produced closer results but due to the time consumed, ITU-R P. 530-16 was chosen. This occurred in both frequencies.

Currently, most of the study on path loss due to rain attenuation were made in temperate location, this can be seen in [6], [47], [68-70]. Tropical location received more rain due to heavy rainfall and caused rain attenuation. Therefore, paper in [71] conducted simulation on to test the channel model for rain attenuation in tropical location specifically in Kalkota and Spina d'Adda for $28 \mathrm{GHz}$ and $28 \mathrm{GHz}$ frequencies by using time series of rain rate prediction as shown in [72]. Method in [72] separated all rain rate data into three segments; constant (C), down (D) and up (U). As known to many, tropical locations received more rainfall than temperate and the author also agreed that rain attenuation is slightly higher there based on the research that had been made. Tropical showed higher attenuation which was 10 to $12 \mathrm{~dB}$ for every $200 \mathrm{~m}$ meanwhile temperate locations only produced $3.5 \mathrm{~dB}$. The authors emphasized on finding a channel model suitable for tropical locations.

\subsection{Haze}

Current air quality throughout the world had declined rapidly. This is the results from open burning, industrial emissions and others. This phenomenon may cause attenuation especially on millimeter wave and had been proved in this paper [73]. In [73], it has provided a mathematical calculation and simulations to prove that haze and fog can also cause attenuation. The characteristics of haze particles as mentioned by authors were it has diameters between $0.001 \sim 10 \mu \mathrm{m}$, particle concentrations between $103 \sim 10 \mathrm{~cm}-3$ and particles mass concentrations between 29.3 166.3 $\mu \mathrm{g} / \mathrm{m} 3$ [74]. As stated in [75], haze particles can be categories into six which are soluble particles, sea salt particles, sulfate particles, insoluble particles, soot and dust particles.

Dust and soot played major roles in causing haze attenuation. It can impact the millimeter wave transmission due to scattering. As mentions before, scattering can be divided into two which are Rayleigh scattering and Mie scattering. The authors suggested that Mie scattering theory can be used to estimate the attenuation coefficient. Mie scattering equation can be seen in (2).

$$
\alpha_{m}=169.2 \times \frac{\mu D^{3}}{\rho \lambda^{4}}\left|\frac{\varepsilon-1}{\varepsilon+2}\right|^{2}
$$

Where:

$$
\begin{aligned}
\alpha_{m} & =\text { Attenuation coefficient } \\
\mu & =\text { Material density } \\
D & =\text { Particles diameter } \\
\rho & =\text { Particles density } \\
\varepsilon & =\text { Relative complex dielectric constant } \\
\lambda & =\text { Frequency wavelength }
\end{aligned}
$$

This calculation had proven the author's theory on haze can be one of the main impacts and also it can caused attenuation in millimeter wave transmission link.

\section{DISCUSSION}

Path loss and shadowing are the challenges in implementing millimeter wave. However, this part will only discussing on the impact on rain and haze attenuation. This is because all of the environmental attenuations can happen in both urban and suburban area.

Based on the reviewed papers, we can see that there are already many research discussed on the impact of rain attenuation in millimeter wave. The researches made already covered most of the frequency spectrum for millimeter wave for example $38 \mathrm{GHz}$ and $75 \mathrm{GHz}$. Both of the frequencies had proven that rain attenuation can occurs in both frequencies but more severe as the frequency getting higher. Moreover, some of the researcher also had been focusing on rain attenuation in both temperate and tropical regions.

However, only one paper did mentions the effect of haze in millimeter wave transmission link. But, there is no concrete evidence to verify the result since there was not further research been made on this paper. Research on haze attenuation is important for many countries especially in South East Asia and China whereas haze is one of the major environmental phenomenon that happening every year. By implementing 5G millimeter wave without taking haze attenuation into consideration may cause major problem for mobile service provider in the future. Besides, the paper only provide theory on haze scattering and mathematical 
modelling to prove that it can caused attenuation. Currently, there are no channel model had been developed that can withstand haze attenuation in millimeter wave.

\section{CONCLUSION}

In conclusion, few challenges on implementing 5G millimeter wave have been reviewed. Communication system using $5 \mathrm{G}$ millimeter wave have a promising future but some challenges in technical as well as path loss and shadowing need to address thoroughly. Further research on environmental attenuation especially haze attenuation is crucial to overcome the limitations on millimeter wave. Moreover, further enhancement on current millimeter wave channel model is essential in order to develop a channel model that can encounter haze attenuation issue.

\section{ACKNOWLEDGEMENT}

This paper was funded by Fundamental Research Grant Scheme (Grant No: FRGS/1/2017/TK04/UNIKL/02/12A). The authors thank our colleagues from Universiti Kuala Lumpur British Malaysian Institute who provided insight and expertise that greatly assisted during the research.

\section{REFERENCES}

[1] Ghosh, R. Ratasuk, B. Mondal, N. Mangalvedhe, T. Thomas, and M. Inc., "LTE-Advanced: Next-Generation Wireless Broadband Technology," IEEE Wirel. Commun., no. 10, pp. 10-22, 2010.

[2] "Requirements for Further Advancements for Evolved Universal Terrestrial Radio Access," vol. 0, no. Release 8, pp. 1-15, 2009.

[3] T. S. Rappaport, Y. Xing, S. Member, G. R. Maccartney, S. Member, and A. F. Molisch, "Overview of Millimeter Wave Communications for Fifth-Generation (5G) Wireless Networks-With a Focus on Propagation Models," vol. 65, no. 12, pp. 6213-6230, 2017.

[4] J. Gubbi, R. Buyya, S. Marusic, and M. Palaniswami, "Internet of Things ( IoT ): A vision , Architectural Elements , and Future Directions,” vol. 29, pp. 1645-1660, 2013.

[5] T. T. Rappaport, "Spectrum Frontiers : The New World of Millimeter-Wave Mobile Communication New York University Tandon School of Engineering," 2016.

[6] T. S. Rappaport et al., "Millimeter Wave Mobile Communications for 5G Cellular: It will Work!," IEEE Access, vol. 1, pp. 335-349, 2013.

[7] T. S. Rappaport, J. N. Murdock, and F. Gutierrez, "State of the Art in 60-GHz Integrated Circuits and Systems for Wireless Communications," Proc. IEEE, vol. 99, no. 8, pp. 1390-1436, 2011.

[8] Z. Pi and F. Khan, "An Introduction to Millimeter Wave Mobile Broadband Systems," no. June, pp. 101-107, 2011.

[9] F. Khan, "LTE For 4G Mobile Broadband : Air Interface Technologies and Performance," pp. 2009, 2009.

[10] J. Stewart, " $5 \mathrm{G}$ will Require New as Well as Established Spectrum Bands , but the Availability of New Bands is not Confirmed One of the Major Motivations for $5 \mathrm{G}$ is to Improve the Performance of Wireless Broadband Services Beyond 2020," 2014. [Online]. Available: http://www.analysysmason.com/AboutUs/News/Newsletter/5G-spectrum-Oct2014/.

[11] Chong, D. I. Laurenson, and S. Mclaughlin, "A New Statistical Based Wideband Spatio-Temporal Clustering Indoor Channel Model for 5ghz WLAN Systems," IEEE J. Sel. Areas Commun., vol. 21, no. 2, pp. 139-150, 2003.

[12] Chong, D. I. Laurenson, and S. Mclaughlin, "Spatio-Temporal Correlation Properties for the 5.2-GHz Indoor Propagation Environments," IEEE Antennas Wirel. Propag. Lett., vol. 2, pp. 114-117, 2003.

[13] C. Chong, C. M. Tan, D. I. Laurenson, S. McLaughlin, M. A. Beach, and A. R. Nix, "A Novel Wideband Dynamic Directional Indoor Channel Model Based on A Markov Process," IEEE Trans. Wirel. Commun., vol. 4, no. 4, pp. $1539-1552,2005$

[14] M. Z. Win and R. A. Scholtz, "On the Robustness of Ultra-Wide Bandwidth Signals in Dense Multipath Environments," IEEE Commun. Lett., vol. 2, no. 9, pp. 51-53, 1998.

[15] M. Z. Win and R. A. Scholtz, "On the Energy Capture of Ultrawide Bandwidth Signals in Dense Multipath Environments," IEEE Commun. Lett., vol. 2, no. 9, pp. 245-247, 1998.

[16] R. J. M. Cramer, R. A. Scholtz, and M. Z. Win, "Evaluation of an Ultra-Wide-Band Propagation Channel," IEEE Trans. Antennas Propag., vol. 50, no. 5, pp. 561-570, 2002.

[17] Cassioli, M. Z. Win, and A. F. Molisch, "The Ultra-Wide Bandwidth Indoor Channel: from Statistical Model to Simulations," IEEE J. Sel. Areas Commun., vol. 20, no. 6, pp. 1247-1257, 2002.

[18] S. K. Yong and C. C. Chong, "An Overview of Multigigabit Wireless Through Millimeter Wave Technology: Potentials and Technical Challenges," Eurasip J. Wirel. Commun. Netw., vol. 2007, 2007.

[19] C. R. Anderson and T. S. Rappaport, "In-Building Wideband Partition Loss Measurements at 2.5 and 60 Ghz," Ieee Trans. Wirel. Commun., vol. 3, no. 3, pp. 922-928, 2004.

[20] J. Violette, R. H. Espeland, R. O. DeBolt, and F. K. Schwering, "Millimeter-Wave Propagation at Street Level in an Urban Environment," IEEE Trans. Geosci. Remote Sens., vol. 26, no. 3, pp. 368-380, 1988 
[21] B. Langen, G. Lober, and W. Herzig, "Reflection and Transmission Behaviour of Building Materials at $60 \mathrm{GHz}$," Proc. 5th IEEE Int. Symp. Pers. Indoor Mob. Radio Commun. (PIMRC '94), vol. 2, pp. 505-509, 1994.

[22] M. Choi, G. Grosskopf, and D. Rohde, "Statistical Characteristics of $60 \mathrm{GHz}$ Wideband Indoor Propagation Channel," Indoor Mob. Radio Commun., pp. 599-603, 2005.

[23] T. Pollack et al., "NICT Indoor $60 \mathrm{GHz}$ Channel Measurements and Analysis update," 2006.

[24] M. Steinbauer, A. F. M. J, and E. Bonekij, "The Double-Directional Radio Channel."

[25] Yang, P. F. M. Smulders, and M. H. A. . Herben, "Frequency Selectivity of 60-GHz LOS and NLOS Indoor Radio Channels," vol. 00, no. c, pp. 2727-2731, 2006.

[26] M. R. Williamson, G. E. Athanasiadou, and A. R. Nix, "Investigating the Effects of Antenna Directivity on Wireless Indoor Communication at 60GHz," pp. 3-7, 1997.

[27] T. Manabe, Y. Miura, and T. Ihara, "Effects of Antenna Directivity and Polarization on Indoor Multipath Propagation Characteristics at 60 Ghz," IEEE J. Sel. Areas Commun., vol. 14, no. 3, pp. 441-447, 1996.

[28] T. Manabe et al., "Polarization Dependence of Multipath Propagation and High-speed Transmission Characteristics of Indoor Millimeter-Wave Channel at 60 GHz," IEEE Trans. Veh. Technol., vol. 44, no. 2, pp. 268-274, 1995.

[29] E. Hossain and M. Hasan, "5G Cellular: Key Enabling Technologies and Research Challenges," no. June, pp. 11-21, 2015.

[30] J. Medbo et al., "Channel Modelling for the Fifth Generation Mobile Communications," 8th Eur. Conf. Antennas Propag. (EuCAP 2014), no. EuCAP, pp. 219-223, 2014.

[31] K. C. Huang and Z. Wang, "Millimeter-Wave Circular Polarized Beam-Steering Antenna Array for Gigabit Wireless Communications," IEEE Trans. Antennas Propag., vol. 54, no. 2, pp. 743-746, 2006.

[32] J.-Y. P. J.-Y. Park, Y. W. Y. Wang, and T. Itoh, "A $60 \mathrm{Ghz}$ Integrated Antenna Array for High-Speed Digital Beamforming Applications," IEEE MTT-S Int. Microw. Symp. Dig. 2003, vol. 3, pp. 1677-1680, 2003.

[33] J. G. Andrews et al., "What Will 5G Be ?," vol. 32, no. 6, pp. 1065-1082, 2014.

[34] Gupta, S. Member, R. K. Jha, and S. Member, "A Survey of 5G Network: Architecture and Emerging Technologies," vol. 3, 2015.

[35] Zhao et al., "28 GHz Millimeter Wave Cellular Communication Measurements for Reflection and Penetration Loss in and around Buildings in New York City," pp. 5163-5167, 2013.

[36] K. C. Allen, N. Deminco, J. R. Hoffman, and Y. Lo, "Building Penetration Loss Measurements at 900 MHz, 11.4 GHz, and $28.8 \mathrm{GHz}, "$ no. May, 1994.

[37] V. Alejos, M. G. Sánchez, and I. Cuiñas, "Measurement and Analysis of Propagation Mechanisms at 40 GHz: Viability of Site Shielding Forced by Obstacles,” vol. 57, no. 6, pp. 3369-3380, 2008.

[38] S. Lu, S. Daniel, C. Patrick, and P. Philip, "Modeling Human Blockers in Millimeter Wave Radio Links," ZTE Communications, vol. 10, no. 4, pp. 23-28, 2012.

[39] Ko et al., "Millimeter-Wave Channel Measurements and Analysis for Statistical Spatial Channel Model in InBuilding and Urban Environments at 28 GHz," IEEE Trans. Wirel. Commun., vol. 1276, 2017.

[40] R. Rudd, K. Craig, M. Ganley, and R. Hartless, "Building Materials and Propagation Final Report Ofcom," no. September, 2014.

[41] C. Larsson, F. Harrysson, B. Olsson, and J. Berg, "An Outdoor-to-Indoor Propagation Scenario at 28 GHz," 8th Eur. Conf. Antennas Propag., no. EuCAP, pp. 3301-3304, 2014.

[42] V. Raghavan et al., "Millimeter Wave Channel Measurements and Implications for PHY Layer Design," pp. $1-14,2017$.

[43] C. U. Bas et al., "Outdoor to Indoor Penetration Loss at $28 \mathrm{GHz}$ for Fixed Wireless Access," 2017.

[44] Haneda et al., "5G 3GPP-like Channel Models for Outdoor Urban Microcellular and Macrocellular Environments," 2016.

[45] T. S. Rappaport, E. Ben-Dor, J. N. Murdock, and Y. Qiao, "38 Ghz and 60 Ghz Angle-Dependent Propagation for Cellular \& Peer-to-Peer Wireless Communications,” IEEE Int. Conf. Commun., pp. 4568-4573, 2012.

[46] E. Ben-Dor, T. S. Rappaport, Y. Qiao, and S. J. Lauffenburger, "Millimeter-Wave 60 Ghz Outdoor and Vehicle AOA Propagation Measurements using A Broadband Channel Sounder," GLOBECOM - IEEE Glob. Telecommun. Conf., pp. 8-13, 2011.

[47] Samimi et al., "28 GHz Propagation Measurements for Outdoor Cellular Communications Using Steerable Beam Antennas in New York City," IEEE Veh. Technol. Conf., pp. 5143-5147, 2013.

[48] O. Landron, M. J. Feuerstein, and T. S. Rappaport, "In Situ Microwave Reflection Coefficient Measurements for SmoothlNand Rough Exterior Wall Surfaces," IEEE 43rd Veh. Technol. Conf., no. 1, 1993.

[49] G. R. M. Jr, J. Zhang, S. Nie, and T. S. Rappaport, "Path Loss Models for 5G Millimeter Wave Propagation Channels in Urban Microcells,” pp. 3948-3953, 2013.

[50] G. R. Maccartney, S. Member, and T. S. Rappaport, "Rural Macrocell Path Loss Models for Millimeter Wave Wireless Communications," vol. 35, no. 7, pp. 1663-1677, 2017.

[51] G. R. Maccartney et al., "Millimeter Wave Wireless Communications : New Results for Rural Connectivity Agenda A Rural Macrocell ( RMa ) Path Loss Model for Frequencies Above $6 \mathrm{GHz}$ in the 3GPP Channel Model Standard Motivation for path loss model in rural areas Existing RMa path lo," Proc. 5th Work. All Things Cell. Oper. Appl. Challenges, Conjunct. with MobiCom, pp. 31-36, 2016.

[52] (3GPP), "Technical Specification Group Radio Access Network; Channel Model for Frequency Spectrum Above 6 Ghz (Release 14)," vol. 0. 2017. 
[53] G. R. MacCartney, T. S. Rappaport, S. Sun, and S. Deng, "Indoor Office Wideband Millimeter-Wave Propagation Measurements and Channel Models at 28 and 73 Ghz for Ultra-Dense 5G Wireless Networks," IEEE Access, vol. 3, no. c, pp. 2388-2424, 2015.

[54] K. S. Paulson and H. Basarudin, "Development of A Heterogeneous Microwave Network Fade Simulation Tool Applicable to Networks That Span Europe," Radio Sci., vol. 46, no. 4, pp. 1-6, 2011.

[55] ITU Radiocommunication Sector ITU-R, "Specific Attenuation Model for Rain For Use In Prediction Methods," Recomm. ITU-R P.638-3, pp. 1-5, 2005.

[56] S. Shrestha and D. Choi, "Rain Attenuation Statistics Over Millimeter Wave Bands in South Korea," J. Atmos. Solar-Terrestrial Phys., vol. 152-153, no. November 2016, pp. 1-10, 2017.

[57] ITU-R, "Propagation Data and Prediction Methods Required for the Design of Terrestrial Line-of-Sight Systems P Series Radiowave Propagation," vol. 16, 2015.

[58] A. R. S. Mello, M. S. Pontes, and R. M. De Souza, "Prediction of Rain Attenuation in Terrestrial Links using Full Rainfall Rate Distribution," vol. 43, no. 25, 2007.

[59] F. Moupfouma, "Electromagnetic Waves Attenuation due to Rain: A Prediction Model for Terrestrial or L.O.S SHF and EHF Radio Communication Links," J Infrared Milli Terahz Waves, pp. 622-632, 2009.

[60] Y. Abdulrahman, T. A. Rahman, S. K. Abdulrahim, and M. R. Ul Islam, "Empirically Derived Path Reduction Factor for Terrestrial Microwave Links Operating at $15 \mathrm{Ghz}$ in Peninsula Malaysia," J. Electromagn. Waves Appl., no. October 2014, pp. 23-37, 2012.

[61] S. H. Lin, "11-GHz Radio: Nationwide Long-Term Rain Rate Statistics and Empirical Calculation of 11-GHz Microwave Rain Attenuation,” BELL Syst. Tech. J. J., vol. 56, no. 9, pp. 1581-1604, 1977.

[62] Y. Abdulrahman, T. A. Rahman, S. K. A. Rahim, and R. Islam, "Rain attenuation predictions on terrestrial radio links: differential equations approach,” Trans. Emerg. Telecommun. Technol., no. January, pp. 293-301, 2012.

[63] Y. A. I. O., B. Olusegun, and N. H. Khamis, "Comparative Analysis of Terrestrial Rain Attenuation at Ku band for Stations in South-Western Nigeria," pp. 27-35, 2008.

[64] Y. Abdulrahman and U. AbdulRahman, Tharek Abdulrahmim, Sharul Kamal Kesavan, "Comparison of Measured Rain Attenuation and ITU-R Predictions on Experimental Microwave Links in Malaysia," Int. J. of Microwave Wirel. Technol., vol. 3, no. 4, pp. 477-483, 2011.

[65] J. S. Mandeep, "Rain Attenuation Statistics Over A Terrestrial Link at 32 . 6 Ghz at Malaysia," IET Microwaves, Antennas Propag., vol. 3, no. January 2008, pp. 1086-1093, 2009.

[66] Y. Abdulrahman, T. A. Rahman, and S. K. Abdulrahim, "Rain Attenuation Measurements Over Terrestrial Microwave Links Operating at 15 Ghz In Malaysia," Int. J. Commun. Syst., 2011.

[67] E. Applications, A. A. Yusuf, and T. A. Rahman, "Statistical Evaluation of Measured Rain Attenuation in Tropical Climate and Comparison with Prediction Models," J. Microwaves, Optoelectron. Electromagn. Appl., vol. 15, no. 2, pp. 123-134, 2016.

[68] W. Roh et al., "Millimeter-Wave Beamforming as an Enabling Technology for 5G Cellular Communications : Theoretical Feasibility and Prototype Results," no. February, pp. 106-113, 2014.

[69] Á. Drozdy, P. Kántor, and J. Bitó, "Effects of Rain Fading in 5G Millimeter Wavelength Mesh Networks."

[70] U. A. Korai, L. Luini, R. Nebuloni, and I. Glesk, "Statistics of Attenuation due to Rain Affecting Hybrid FSO / RF link : Application for 5G networks," no. 4, pp. 1789-1792, 2017.

[71] D. Nandi and A. Maitra, "Study of Rain Attenuation Effects for 5G Mm- Wave Cellular Communication in Tropical Location," no. 2006, pp. 10-13, 2018.

[72] D. D. A. Maitra, "Time Series Prediction of Rain Rate During Rain Events at A Tropical Location," vol. 6, no. June, pp. 1710-1716, 2012.

[73] L. Lin and Z. Li, "Study of Transmission Effects of Millimeter Wave through Fog and Haze," pp. 1591-1596, 2016.

[74] W. Chen, "An analysis of gas absorption by a liquid aerosol in a stationary environment," vol. 36, pp. 3671-3683, 2002.

[75] T. Mao, D. Zhou, and Z. Niu, "The Calculation Model of the Attenuation Due to Clouds or Fog and the Analysis of its Characteristic," pp. 332-334, 2004.

[76] R.K. Crane, Electromagnetic Wave Propagation Through Rain, New York: Wiley-Interscience, 1996, pp 245-259.

\section{BIOGRAPHIES OF AUTHORS}

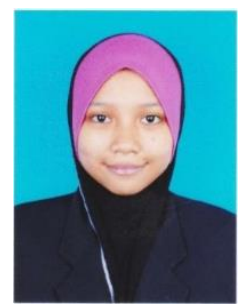

Siti Fatimah Nordin currently is a Master student at Universiti Kuala Lumpur British Malaysian Institute. She was awarded with Bachelor of Engineering Technology (Hons) in Electonics and Diploma of Engineering Technology in Electrical and Electronics from Universiti Kuala Lumpur British Malaysian Institute in 2004 and 2018, respectively. Her current research interest includes telecommunication, wireless communication, millimeter wave and $5 \mathrm{G}$. 


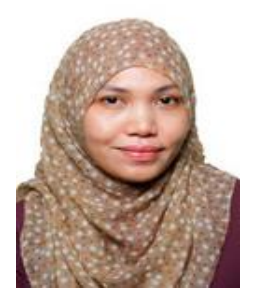

Dr Zuhanis Binti Mansor joined Universiti Kuala Lumpur British Malaysian Institute (UNIKL BMI) as a member of lecturing staff in June 2002 and is currently a Senior Lecturer of the Communication Technology Section at UniKL BMI. She received BEng and MEng degrees in Electrical \& Electronics from the University Teknology Malaysia (UTM). Zuhanis received a Ph.D. from the University of Bristol in 2003 for research into MIMO Exploitation of 3D Multipath Statistics in a Heterogeneous LTE-Advanced Network. She has worked with major telecommunication companies such as TIME Telecom and MIMOS, Malaysia between 1994 and 2002. Her main areas of research are wireless communications mainly in uplink and downlink of Physical layer. Her research interests include OFDMA and SC-FDMA, multiple antenna techniques, radio propagation, antennas, MIMO, LTE, 4G, 5G communications systems and mmWave. She has secured funding as principal and co-investigator in the above areas. She is supervising $2 \mathrm{PhD}$ students and 1 master student

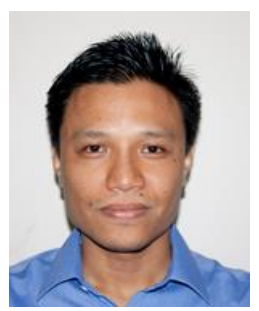

Dr Aizat Faiz Ramli is a senior lecturer at Electronics Technology, Universiti Kuala Lumpur British Malaysian Institute. He is currently Research and innovation Coordinator. Dr. Aizat Faiz was awarded PhD from the University of York, United Kingdom in 2014 and a Master of Engineering degree in Electronic Engineering (MEng) from University of Hull, United Kingdom. His area of expertise and current research interest includes cognitive radio, artificial intelligence, wireless sensor networks and Internet of Things (IOT).

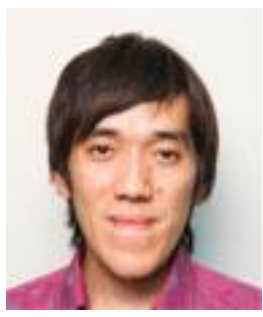

Dr Hafiz Basarudin is a senior lecturer at Telecommunication Technology Department at Universiti Kuala Lumpur British Malaysian Institute. He is a graduate from Universiti Kuala Lumpur British Malaysian Institute with Higher National Diploma in Electronics Engineering in 2003. Dr Hafiz was awarded PhD and Master from University of Hull, United Kingdom in 2008 and 2012, respectively. He was a former Head of Postgraduate and APEL section on Universiti Kuala Lumpur British Malaysian Institute and ended his term in 2018. His area of expertise and current research interest includes telecommunication, terrestrial and satellite links wave propagation and artificial intelligence. 